\title{
Knowledge, Attitude, Practice, and Perceived Barriers of Colorectal Cancer Screening among Family Physicians in National Guard Health Affairs, Riyadh
}

\author{
Eyad Demyati \\ Department of Family Medicine and Primary Health Care, King Abdulaziz Medical City, National Guard Health Affairs, \\ P.O. Box 22490, Riyadh 11426, Saudi Arabia
}

Correspondence should be addressed to Eyad Demyati; dr.eyadd@gmail.com

Received 4 May 2014; Revised 18 August 2014; Accepted 8 September 2014; Published 28 September 2014

Academic Editor: Samuel Y. S. Wong

Copyright (C) 2014 Eyad Demyati. This is an open access article distributed under the Creative Commons Attribution License, which permits unrestricted use, distribution, and reproduction in any medium, provided the original work is properly cited.

\begin{abstract}
Objectives. The objective of this study is to explore the current knowledge, attitude, and practice of family physicians working in family medicine clinics in National Guard Health Affairs (NGHA), Riyadh, toward colorectal cancer (CRC) screening and to identify the barriers of the screening. Methods. Data were collected using a validated self-administered questionnaire adopted from the National Cancer Institute in USA, customized by adding and eliminating questions to be in line with the institution (NGHA) characteristics. Results. Of the 130 physicians, $56.2 \%$ of the physicians were not practicing CRC screening although $94.6 \%$ considered CRC screening effective. Board certified physicians had higher knowledge score and were practicing CRC screening more when compared to other physicians. Physicians who reported practicing CRC screening scored more on the knowledge score than those not practicing. Male physicians scored better on attitude score than female physicians. The study found that barriers were cited in higher rates among physicians not practicing CRC screening compared with practicing physicians. Lack of patients' awareness was the most cited barrier. Conclusion. Large percentage of family physicians in this study do not practice CRC screening, despite the knowledge level and the positive attitude.
\end{abstract}

\section{Introduction}

"Cancer is a leading cause of death worldwide" [1]. Colorectal cancer (CRC) ranks fourth in the most common cause of death due to cancers worldwide [2]. In USA, CRC is the second leading cause of cancer-related deaths in cancers affecting both male and female [3].

According to the Saudi Cancer Registry, CRC ranks second in the most common cancers among Saudis after breast cancer and first among Saudi males with constant rise in the incidence for the past few years. Furthermore, the overall survival rate $(44.6 \%)$ is generally lower than the typically reported survival rates all over the world. CRC in Saudi Arabia present late with metastasis and obstruction in percentages more than what is reported in western communities. Nearly, $40 \%$ of CRC diagnosed were equal to or below 50 years of age with mean age of 58 years, which is lower than developed countries [4-8].
CRC is an ideal tumor for screening, with its high incidence and long time between adenomatous polyp and carcinoma, and early diagnosis by screening can reduce incidence and mortality of the disease [9-14].

Family physicians have a key role in screening practice due to frequent contact with large proportion of population. Furthermore, the involvement of family physicians in screening program implementation has been recommended by several guidelines [9].

However, physicians-reported CRC screening recommendation rates in the literature are still below the demand if a major impact on CRC mortality is targeted [15]. Moreover, this is the first local study in Saudi Arabia that is looking for data regarding CRC screening practice. The aim of this study is to explore the current knowledge, attitude and practice of family physicians toward CRC screening and to identify the barriers of conducting such a screening. 


\section{Methods}

A cross-sectional descriptive study was carried out among family physicians working in family medicine clinics in National Guard Health Affairs (NGHA), Riyadh, Saudi Arabia between February and March 2013. All 170 family physicians were included in the study without sampling.

A validated questionnaire was adopted from the National Cancer Institute in USA, customized by adding and eliminating questions to be in line with the institution (NGHA) characteristics. A pilot study on 10 physicians was conducted to check understanding of the questionnaire, resulted in some vocabularies replacement and format enhancing to avoid confusion. Then the questionnaire was reviewed and approved by tow reviewers from King Abdulla International Medical Research Center (KAIMRC). It contains demographic characteristics, questions to assess the knowledge, attitude, current practice and barriers of CRC screening. Questionnaires were handed out to the physicians during working hours by the researcher or an assigned nurse and collected in the next following day. It was self-administered and takes about 10 minutes to be completed.

Data management and statistical analysis were carried out using Statistical Package for Social Sciences (SPSS) software version 20.0. Categorical variables were presented as frequencies and percentages, Chi-Square test $\left(\chi^{2}\right)$ used to explore the association between variables.

Knowledge score: correct answers marked with 1 and wrong answers with 0 . A sum of all knowledge questions was calculated for each participant. Knowledge score was computed on the basis of 11 questionnaire items, the answers were evaluated according to the Centers for Disease Control and prevention (CDC) and United States Preventive Services Task Force (USPSTF) Guidelines recommendations.

Attitude score: Answers with positive attitude marked with 1 and negative attitude marked with 0 . A sum of all attitude questions was calculated for each participant. Attitude score was computed on the basis of 8 questionnaire items.

Means of scores were compared between groups using student $t$-test $(t) . P$-value at 0.05 or less was considered to be significant.

Permission from KAIMRC in Riyadh was obtained. Questionnaire cover sheet of the study explained that the participation of the physicians considered as a consent form of agreement.

\section{Results}

3.1. Demographics. The study included 170 physicians; the response rate was $76 \%$. Out of 130 physicians, 68 (52.3\%) were females, 51 (39\%) were family medicine board certified, and 56 (43\%) were MBBS holders (Table 1). Mean age was 38 years (SD 7.4).

3.2. Knowledge. The mean value results for the knowledge score was founded to be 5.02 with standard deviation of 2.73 and ranged between $0-11$ (Table 2).
TABle 1: Medical degree of the participated physicians.

\begin{tabular}{lcc}
\hline Medical degree & Number of physicians & $\%$ \\
\hline Family medicine board & 51 & 39 \\
Other & & \\
$\quad$ MBBS & 56 & 43 \\
$\quad$ MRCGP & 23 & 18 \\
Total & $\mathbf{1 3 0}$ & $\mathbf{1 0 0}$ \\
\hline
\end{tabular}

TABLE 2: Knowledge score items and numbers of correct answers.

\begin{tabular}{lc}
\hline Knowledge item & $\begin{array}{c}\text { Correct answers } \\
N(\%)\end{array}$ \\
\hline $\begin{array}{l}\text { Fifty years of age as starting age for } \\
\text { screening }\end{array}$ & $102(78.5)$ \\
Awareness about stopping age for \\
screening \\
$\begin{array}{l}\text { Seventy-five years of age as stopping age } \\
\text { for screening }\end{array}$ \\
Awareness about Fecal Occult Blood \\
Testing \\
$\begin{array}{l}\text { FOBT): } \\
\quad \text { Guaiac FOBT }\end{array}$ \\
$\quad$ Fecal immunochemical testing \\
$\quad$ FOBT office card \\
$\quad$ FOBT home kit \\
Ordering 3 samples for each FOBT \\
Screening interval for each screening \\
modality \\
$\quad$ FBOT annually \\
Flexible Sigmoidoscopy every 5 years \\
Colonoscopy every 10 years
\end{tabular}

Board certified physicians had higher knowledge score than other physicians $(t=2.6 ; P=0.009)$.

Physicians who reported practicing CRC screening scored more on the knowledge score than those not practicing, $(t=2.7 ; P=0.007)$.

Physicians influenced by USPSTF Recommendations achieved better knowledge score compared to those who were $\operatorname{not}(t=3.1 ; P=0.002)$.

Physicians influenced by their patients' preference for CRC screening also achieved better knowledge score when compared to those who were not $(t=3.2 ; P=0.002)$.

Although not statistically significant, male physicians had higher knowledge score than female $(t=1.8 ; P=0.071)$ (Table 3).

3.3. Attitude. Among the sample studied, 123 physicians (94.6\%) considered CRC screening for asymptomatic average-risk patients to be effective and 106 (81.5\%) prefer having structured screening program over opportunistic screening.

Among the screening modalities, colonoscopy was cited as "very effective" by 123 (94.6\%). Flexible sigmoidoscopy was 
TABLE 3: Knowledge score compared with different physicians' factors.

\begin{tabular}{|c|c|c|c|}
\hline \multirow{2}{*}{ Factors } & \multicolumn{3}{|c|}{ Knowledge score } \\
\hline & Mean (SD) & $t$ & $P$ \\
\hline \multicolumn{4}{|l|}{ Gender } \\
\hline Male & $5.47(2.8)$ & \multirow{2}{*}{1.82} & \multirow{2}{*}{0.071} \\
\hline Female & $4.60(2.6)$ & & \\
\hline \multicolumn{4}{|l|}{ Age } \\
\hline$<40$ years & $5.25(2.4)$ & \multirow{2}{*}{1.17} & \multirow{2}{*}{0.245} \\
\hline$>40$ years & $4.68(3.1)$ & & \\
\hline \multicolumn{4}{|c|}{ Family medicine board } \\
\hline Yes & $5.78(2.8)$ & \multirow{2}{*}{2.64} & \multirow{2}{*}{0.009} \\
\hline No & $4.52(2.6)$ & & \\
\hline \multicolumn{4}{|c|}{ Performing CRC screening } \\
\hline Yes & $5.74(2.7)$ & \multirow{2}{*}{2.73} & \multirow{2}{*}{0.007} \\
\hline No & $4.45(2.6)$ & & \\
\hline \multicolumn{4}{|c|}{ Having a reminder system } \\
\hline Yes & $6.18(2.9)$ & \multirow{2}{*}{1.25} & \multirow{2}{*}{0.215} \\
\hline No & $5.29(2.6)$ & & \\
\hline \multicolumn{4}{|c|}{ Influenced by USPSTF } \\
\hline Yes & $5.28(2.7)$ & \multirow{2}{*}{3.12} & \multirow{2}{*}{0.002} \\
\hline No & $2.85(1.9)$ & & \\
\hline \multicolumn{4}{|c|}{$\begin{array}{l}\text { Influenced by American Cancer } \\
\text { Society }\end{array}$} \\
\hline Yes & $5.12(2.7)$ & \multirow{2}{*}{1.23} & \multirow{2}{*}{0.220} \\
\hline No & $4.20(2.9)$ & & \\
\hline \multicolumn{4}{|c|}{ Influenced by colleagues practice } \\
\hline Yes & $4.76(2.7)$ & \multirow[t]{2}{*}{1.53} & \multirow[t]{2}{*}{0.127} \\
\hline No & $5.53(2.8)$ & & \\
\hline \multicolumn{4}{|c|}{$\begin{array}{l}\text { Influenced by patient's preference } \\
\text { of screening test }\end{array}$} \\
\hline Yes & $5.45(2.8)$ & \multirow{2}{*}{3.15} & \multirow{2}{*}{0.002} \\
\hline No & $3.97(2.2)$ & & \\
\hline
\end{tabular}

considered "very effective" by 58 (44.6\%) and $42(32.3 \%)$ only for Fecal Occult Blood Testing (FOBT).

The mean value of the attitude score was found to be 6.95 with standard deviation of 1 and ranged between 4 and 8 (Table 4).

Male physicians scored better on attitude score than female $(t=2.3 ; P=0.025)$.

Physicians aged 40 years and above had better attitude than younger physicians $(t=2 ; P=0.047)$.

Physicians who reported having a reminder system for CRC screening scored better attitude than those who did not, $(t=3.4, p=0.001)$ (Table 5).

3.4. Practice. Around more than half (56.2\%) of the physicians are not practicing CRC screening for asymptomatic average-risk patients.
TABLE 4: Attitude score items and numbers of physicians with positive attitude.

\begin{tabular}{lc}
\hline Attitude items & $\begin{array}{c}\text { Positive attitude } \\
N(\%)\end{array}$ \\
\hline $\begin{array}{l}\text { CRC screening is effective for asymptomatic } \\
\text { average risk patient }\end{array}$ & $123(94.6)$ \\
FOBT is effective & $123(94.6)$ \\
Flexible sigmoidoscopy is effective & $123(94.6)$ \\
Colonoscopy is effective & $128(98.5)$ \\
Double-contrast barium enema is effective & $90(69.2)$ \\
CT-colonography & $91(70)$ \\
Preferring structured screening program & $106(81.5)$ \\
over opportunistic & $120(92.3)$ \\
Colonoscopy is the best available screening & \\
test &
\end{tabular}

FOBT is discussed more as screening modality $(80.8 \%)$ in comparison with colonoscopy (76.90\%) and flexible sigmoidoscopy (35.4\%). Majority of the physicians conduct FOBT by delivering stool samples to the labs (90\%).

Board certification contributed significantly to practicing CRC screening when compared to other physicians $\left(\chi^{2}=\right.$ 7.65; $P=0.005)$.

Physicians whose practice was influenced by USPSTF and and American Cancer Society recommendations reported practicing CRC screening more than those who were not influenced by these resources $\left(\chi^{2}=4.86 ; P=0.025\right)$ and $\left(\chi^{2}=3.92 ; P=0.041\right)$, respectively.

Although lacking statistical significance, male physicians reported practicing CRC screening more than female physicians $\left(\chi^{2}=2.9 ; P=0.063\right)$ (Table 6).

When asked about barriers to practice CRC screening, $80 \%$ of physicians who did not perform the screening believed time was a barrier compared to $56 \%$ of those who actually practice the CRC screening $\left(\chi^{2}=9.29 ; P=0.002\right)$.

Also, $70 \%$ of physicians who did not practice the screening thought that the patients do not want to discuss colorectal cancer. This belief was noted among only $49 \%$ of physicians who practiced CRC screening $\left(\chi^{2}=5.78 ; P=0.013\right)$.

Nearly, $77 \%$ of physicians who did not practice the screening reported that patients are having difficulty understanding the information about CRC screening, compared to only $45.6 \%$ of physicians who do practice the screening $\left(\chi^{2}=\right.$ 13.29; $P<0.00)$.

Moreover, $60.3 \%$ of physicians not practicing CRC screening believed that patients do not perceive CRC as a serious health threat, compared to only $36.8 \%$ of physicians who practice CRC screening $\left(\chi^{2}=7.03 ; P=0.007\right)$.

When asked about having a clear policy and procedure for CRC screening in their workplace, $86.3 \%$ of physicians not practicing CRC screening reported that there is no policy in their workplace compared to $65 \%$ of physicians who practice CRC screening $\left(\chi^{2}=8.25 ; P=0.004\right)$. 
TABLE 5: Attitude score compared with different physicians' factors.

\begin{tabular}{|c|c|c|c|}
\hline \multirow{2}{*}{ Factor } & \multicolumn{3}{|c|}{ Attitude score } \\
\hline & Mean (SD) & $t$ & $P$ \\
\hline \multicolumn{4}{|l|}{ Gender } \\
\hline Male & $7.18(0.9)$ & \multirow{2}{*}{2.27} & \multirow{2}{*}{0.025} \\
\hline Female & $6.75(1.2)$ & & \\
\hline \multicolumn{4}{|l|}{ Age } \\
\hline$<40$ years & $6.81(1.2)$ & \multirow{2}{*}{2.00} & \multirow{2}{*}{0.047} \\
\hline$>40$ years & $7.17(0.9)$ & & \\
\hline \multicolumn{4}{|c|}{ Family medicine board } \\
\hline Yes & $7.12(1.1)$ & \multirow{2}{*}{1.38} & \multirow{2}{*}{0.170} \\
\hline No & $6.85(1.1)$ & & \\
\hline \multicolumn{4}{|c|}{ Performing CRC screening } \\
\hline Yes & $7.09(1.0)$ & \multirow{2}{*}{1.24} & \multirow{2}{*}{0.218} \\
\hline No & $6.85(1.1)$ & & \\
\hline \multicolumn{4}{|c|}{ Having a reminder system } \\
\hline Yes & $7.59(0.5)$ & \multirow{2}{*}{3.44} & \multirow{2}{*}{0.001} \\
\hline No & $7.00(1.1)$ & & \\
\hline \multicolumn{4}{|c|}{ Influenced by USPSTF } \\
\hline Yes & $7.00(1.1)$ & \multirow[t]{2}{*}{1.21} & \multirow[t]{2}{*}{0.230} \\
\hline No & $6.62(1.3)$ & & \\
\hline \multicolumn{4}{|c|}{$\begin{array}{l}\text { Influenced by American Cancer } \\
\text { Society }\end{array}$} \\
\hline Yes & $7.03(1.0)$ & \multirow[t]{2}{*}{2.12} & \multirow[t]{2}{*}{0.036} \\
\hline No & $6.40(1.4)$ & & \\
\hline \multicolumn{4}{|c|}{$\begin{array}{l}\text { Influenced by availability of } \\
\text { providers for test other than } \\
\text { FOBT }\end{array}$} \\
\hline Yes & $6.97(1.1)$ & \multirow{2}{*}{0.48} & \multirow{2}{*}{0.631} \\
\hline No & $6.84(1.2)$ & & \\
\hline \multicolumn{4}{|c|}{ Influenced by colleagues practice } \\
\hline Yes & $6.99(1.1)$ & \multirow{2}{*}{1.53} & \multirow{2}{*}{0.609} \\
\hline No & $6.88(1.2)$ & & \\
\hline \multicolumn{4}{|c|}{$\begin{array}{l}\text { Influenced by patients' } \\
\text { preference of screening test }\end{array}$} \\
\hline Yes & $7.03(1.0)$ & \multirow{2}{*}{1.28} & 0.202 \\
\hline No & $6.76(1.2)$ & & \\
\hline
\end{tabular}

Also, physicians who do not practice the screening were more to report shortage of trained providers to conduct further screening procedures other than FOBT (77.8\% compared to $54.4 \%$ of those who practice CRC screening) $\left(\chi^{2}=7.93\right.$; $P=0.004)$ (Table 7).

3.5. Perceived Barriers. Among patients related barriers for CRC screening, $92.4 \%$ of physicians reported that patients are not aware of CRC screening and (63.1\%) commented that their patients have difficulties understanding the information about CRC screening.
TABLE 6: Practice compared with different physicians' factors.

\begin{tabular}{lccc}
\hline Factors & \multicolumn{3}{c}{ Practicing CRC screening } \\
& $\%$ & $\chi^{2}$ & $P$ \\
\hline Gender & & & \\
$\quad$ Male & 56.1 & 2.904 & 0.063 \\
$\quad$ Female & 43.9 & & \\
Age & & & \\
$\quad<40$ years & 64.9 & 1.357 & 0.162 \\
$\quad>40$ years & 35.1 & & \\
Family medicine board & & & \\
$\quad$ Yes & 52.6 & 7.646 & 0.005 \\
$\quad$ No & 47.4 & & \\
Considering screening effective & & & \\
$\quad$ Yes & 98.2 & 2.626 & 0.107 \\
$\quad$ No & 1.8 & & \\
Influenced by USPSTF & & & \\
$\quad$ Yes & 96.5 & 4.863 & 0.025 \\
$\quad$ No & 3.5 & & \\
Influenced by American Cancer & & & \\
Society & & & \\
$\quad$ Yes & & & \\
$\quad$ No & & & \\
Influenced by availability of providers & & & \\
for tests other than FOBT & & & \\
$\quad$ Yes & & & \\
$\quad$ No & & & \\
$\quad$ Influenced by colleagues practice & & & \\
$\quad$ Yes & & & \\
$\quad$ No & & & \\
Influenced by patient's preference of & & & \\
screening test & & & \\
\hline
\end{tabular}

In relation to workplace related barriers, not having a reminder system was the top barrier on the list with $(86 \%)$ followed by unavailability of CRC screening policy and procedure (76.9\%). Seventy percent of physicians reported that they do not have enough time to discuss CRC screening with their patients (Table 8).

\section{Discussion}

Several studies have been done in Saudi Arabia in regard to CRC, and all of them concluded and highlighted the importance of screening $[4,5,7,8]$. This is the first study that looked at the current knowledge, attitude, practice, and perceived barriers of physicians in Saudi Arabia in order to close the gap for a better screening.

The response rate was $76 \%$, higher than that obtained from similar studies which involved more centers and more than one city $[9,16,17]$. 
TABLE 7: Barriers among practicing physicians compared with nonpracticing physicians.

\begin{tabular}{|c|c|c|c|}
\hline Barriers & $\%$ & $\chi^{2}$ & $P$ \\
\hline \multicolumn{4}{|l|}{ Time } \\
\hline Practicing & 56 & \multirow{2}{*}{9.285} & \multirow{2}{*}{0.002} \\
\hline Nonpracticing & 80 & & \\
\hline \multicolumn{4}{|c|}{$\begin{array}{l}\text { My patients do not want to } \\
\text { discuss CRC screening= }\end{array}$} \\
\hline Practicing & 49 & \multirow{2}{*}{5.775} & \multirow[t]{2}{*}{0.013} \\
\hline Nonpracticing & 70 & & \\
\hline \multicolumn{4}{|c|}{$\begin{array}{l}\text { My patients have difficulty } \\
\text { understanding the information } \\
\text { about CRC screening }\end{array}$} \\
\hline Practicing & 45.6 & \multirow{2}{*}{13.291} & \multirow{2}{*}{0.000} \\
\hline Nonpracticing & 76.7 & & \\
\hline \multicolumn{4}{|c|}{$\begin{array}{l}\text { My patients are unaware of CRC } \\
\text { screening }\end{array}$} \\
\hline Practicing & 91.2 & \multirow{2}{*}{0.167} & \multirow{2}{*}{0.465} \\
\hline Nonpracticing & 93.2 & & \\
\hline \multicolumn{4}{|c|}{$\begin{array}{l}\text { My patients do not perceive CRC } \\
\text { as a serious health threat }\end{array}$} \\
\hline Practicing & 36.8 & \multirow{2}{*}{7.030} & \multirow{2}{*}{0.007} \\
\hline Nonpracticing & 60.3 & & \\
\hline \multicolumn{4}{|c|}{$\begin{array}{l}\text { There is no CRC screening policy } \\
\text { or procedure in my workplace }\end{array}$} \\
\hline Practicing & 65 & \multirow{2}{*}{8.249} & \multirow{2}{*}{0.004} \\
\hline Nonpracticing & 86.3 & & \\
\hline \multicolumn{4}{|c|}{$\begin{array}{l}\text { There is no reminder system in } \\
\text { my workplace }\end{array}$} \\
\hline Practicing & 86 & \multirow{2}{*}{0.003} & \multirow{2}{*}{0.576} \\
\hline Nonpracticing & 86.3 & & \\
\hline \multicolumn{4}{|c|}{$\begin{array}{l}\text { Patients are not followed up } \\
\text { through to complete CRC } \\
\text { screening }\end{array}$} \\
\hline Practicing & 68.4 & \multirow{2}{*}{3.187} & \multirow{2}{*}{0.058} \\
\hline Nonpracticing & 82 & & \\
\hline \multicolumn{4}{|c|}{$\begin{array}{l}\text { Shortage in trained providers for } \\
\text { endoscopic tests as a first test }\end{array}$} \\
\hline Practicing & 54.4 & \multirow{2}{*}{7.928} & \multirow{2}{*}{0.004} \\
\hline Nonpracticing & 77.8 & & \\
\hline \multicolumn{4}{|c|}{$\begin{array}{l}\text { Shortage in trained providers for } \\
\text { endoscopic tests as a follow-up } \\
\text { test }\end{array}$} \\
\hline Practicing & 58 & \multirow[t]{2}{*}{1.048} & \multirow[t]{2}{*}{0.200} \\
\hline Nonpracticing & 66.7 & & \\
\hline
\end{tabular}

This study found that CRC screening is underutilized since around more than half of the study subjects were not practicing CRC screening despite a strong evidence supporting the effectiveness of the screening, physicians' knowledge, and their positive attitude toward its effectiveness, which is in accordance with findings in the literature $[9,17,18]$.
Knowledge of the physicians was acceptable, and main deficiency was on the age of stopping CRC screening which is similar to Klabunde et al. findings [17].

Board certified physicians achieved higher knowledge score than physicians with lower certification, which highlights their role in educating other physicians about the importance of screening. Physicians influenced by USPSTF recommendations achieved better knowledge score compared to those who were not, and this goes in line with considering the CDC guideline as a reference for knowledge evaluation in this study and also reflects the importance of USPSTF as a trusted source of information. Physicians with a higher knowledge score were more patient-oriented in considering their patients' preference for screening, which will increase patient involvement in decision making, and that will help build a stronger doctor patient relationship. Result showed significant positive association between knowledge score and practicing CRC screening which reflects the importance of physicians' education for the improvement of CRC screening, and this finding was in accordance with the literature [19].

In general, physicians have a positive attitude toward CRC screening reflected by the attitude score. Positive attitude toward CRC screening was associated with being male; this might be due to the fact that, under the setting of NGHA clinics, female physicians are almost exclusively treating female subjects. Among female patients, other cancers (e.g., breast and cervical cancers) are of greater significance than colorectal cancer which has higher incidence among male subjects. Also, physicians aged 40 years and above had better attitude than younger physicians, which may indicate the importance of experience; there is similar finding in Greece [20]. Physicians who reported having a reminder system for CRC screening scored better attitude than those did not; this is supporting Sarfaty and Wender finding that CRC screening can be improved by implementing a reminder system targeting both doctors and patients [21]. In contrary to knowledge score, attitude score showed positive association with practicing CRC screening but the result was statistically insignificant.

Most of the physicians consider colonoscopy to be the most effective screening test, followed by flexible sigmoidoscopy. Only one-third of physicians found FOBT to be "very effective."

In contrary, FOBT is the most used test followed by colonoscopy, which is similar to what Klabunde et al. and Federici et al. found $[9,17]$. This might be due to more patients' acceptance or the availability of the FOBT in comparison to colonoscopy.

The study found that barriers were cited in higher rates among physicians not practicing CRC screening compared with practicing physicians. Lack of patients' awareness was the most cited barrier, which was also highlighted in the literature [22].

Not having a reminder system was reported by $86 \%$. Taking that into consideration, tackling and finding solutions to overcome these barriers might improve the CRC screening.

Around $81 \%$ cited that they prefer structured screening program over opportunistic. Miles et al. concluded that the most effective way of achieving reduction in cancer related 
TABle 8: Perceived barriers reported by the physicians.

\begin{tabular}{lcc}
\hline Barriers & No. & \\
\hline Patients related & 120 & 79 \\
$\quad$ Patients are not aware of CRC screening $(n=130)$ & 82.4 \\
Patients do not want to discuss CRC screening $(n=130)$ & 60.7 \\
Patients have difficulty understanding the information about CRC screening $(n=130)$ & 63.1 \\
Patients do not perceive CRC screening as a serious health threat $(n=130)$ & 50 \\
Workplace related & 112 \\
$\quad$ Not having a reminder system $(n=130)$ & 100 \\
$\quad$ Unavailability of CRC screening policy and procedure $(n=130)$ & 98 \\
Patients are not followed up through to complete CRC Screening $(n=129)$ & 87 \\
Shortage in trained providers for endoscopic as a first test $(n=129)$ & 81 \\
Shortage in trained providers for endoscopic as a follow-up test $(n=129)$ & 76.9 \\
Not having enough time to discuss CRC screening $(n=130)$ & 67.5 \\
\hline
\end{tabular}

mortality is by providing screening as part of an organized program [23].

\section{Study Limitations}

(1) The study was carried out in one institution in one city of Saudi Arabia and does not necessarily reflect general population.

(2) Study design (cross-sectional) has limited internal validity and it is sensitive to a variety of biases.

(3) Data collection tool was self-administered and lack of observation carries a risk of recalling bias or contamination by the participants.

\section{Conclusion and Recommendations}

Unfortunately, large percentage of family physicians in this study do not recommend CRC screening, despite the knowledge level and the positive attitude. This is pointing to the importance of increasing the attention of the doctors about their crucial rule in CRC prevention. Moreover, patients' involvement and awareness are of a good impact on the CRC screening process. Therefore, we recommend increasing the patients' awareness by the mass media and health campaigns and considering a national organized screening program that will help the physicians to achieve a desirable outcome.

\section{Conflict of Interests}

The author has no conflict of interests to declare regarding the publication of this paper.

\section{Acknowledgments}

The author would like to express his deep gratitude to Dr. Imad Addin Abdulmajeed and Dr. Saeed Ur Rahman for their help with this paper.

\section{References}

[1] WHO, "Cancer Fact sheet," 2012, http://www.who.int/mediacentre/factsheets/fs297/en.

[2] GOLOBOCAN, “GOLOBOCAN 2008," 2008, http://globocan .iarc.fr/Default.aspx.

[3] CDC, “Colorectal Cancer Statistics," 2008, http://www.cdc.gov/ cancer/colorectal/statistics/index.htm.

[4] M. H. Mosli and M. S. Al-Ahwal, "Colorectal cancer in the Kingdom of Saudi Arabia: need for screening," Asian Pacific Journal of Cancer Prevention, vol. 13, no. 8, pp. 3809-3813, 2012.

[5] K. S. Almurshed, "Colorectal cancer: case-control study of sociodemographic, lifestyle and anthropometric parameters in Riyadh," Eastern Mediterranean Health Journal, vol. 15, no. 4, pp. 817-826, 2009.

[6] E. M. Ibrahim, A. A. Zeeneldin, T. R. El-Khodary, A. M. Al-Gahmi, and B. M. Bin Sadiq, "Past, present and future of colorectal cancer in the Kingdom of Saudi Arabia," Saudi Journal of Gastroenterology, vol. 14, no. 4, pp. 178-182, 2008.

[7] A. M. Aljebreen, "Clinico-pathological patterns of colorectal cancer in Saudi Arabia: younger with an advanced stage presentation," Saudi Journal of Gastroenterology, vol. 13, no. 2, pp. 84-87, 2007.

[8] H. S. Al-Eid and A. Al-Zahrani, Cancer Incidence and Survival Report Saudi Arabia, 2007, http://www.scr.org.sa.

[9] A. Federici, P. G. Rossi, F. Bartolozzi, S. Farchi, P. Borgia, and G. Guasticchi, "Survey on colorectal cancer screening knowledge, attitudes, and practices of general practice physicians in Lazio, Italy," Preventive Medicine, vol. 41, no. 1, pp. 30-35, 2005.

[10] O. Kronborg, C. Fenger, J. Olsen, O. D. Jørgensen, and O. Søndergaard, "Randomised study of screening for colorectal cancer with faecal-occult-blood test," The Lancet, vol. 348, no. 9040, pp. 1467-1471, 1996.

[11] L. A. Mack, H. Stuart, and W. J. Temple, "Survey of colorectal cancer screening practices in a large Canadian urban centre," Canadian Journal of Surgery, vol. 47, no. 3, pp. 189-194, 2004.

[12] J. S. Mandel, J. H. Bond, T. R. Church et al., "Reducing mortality from colorectal cancer by screening for fecal occult blood," New England Journal of Medicine, vol. 328, no. 19, pp. 1365-1371, 1993.

[13] J. S. Mandel, T. R. Church, J. H. Bond et al., "The effect of fecal occult-blood screening on the incidence of colorectal cancer," The New England Journal of Medicine, vol. 343, no. 22, pp. 1603$1607,2000$. 
[14] B. Towler, L. Irwig, P. Glasziou, J. Kewenter, D. Weller, and C. Silagy, "A systematic review of the effects of screening for colorectal cancer using the faecal occult blood test, Hemoccult," British Medical Journal, vol. 317, no. 7158, pp. 559-565, 1998.

[15] D. Mauri, G. Pentheroudakis, A. Milousis et al., "Colorectal cancer screening awareness in European primary care," Cancer Detection and Prevention, vol. 30, no. 1, pp. 75-82, 2006.

[16] M. J. Sladden and J. E. Ward, "Australian general practitioners' views and use of colorectal cancer screening tests," Medical Journal of Australia, vol. 170, no. 3, pp. 110-113, 1999.

[17] C. N. Klabunde, P. S. Frame, A. Meadow, E. Jones, M. Nadel, and S. W. Vernon, "A national survey of primary care physicians' colorectal cancer screening recommendations and practices," Preventive Medicine, vol. 36, no. 3, pp. 352-362, 2003.

[18] F. Eisinger, J.-Y. Blay, J.-F. Morère et al., "Cancer screening in France: subjects' and physicians' attitudes," Cancer Causes and Control, vol. 19, no. 4, pp. 431-434, 2008.

[19] C. Woodrow, L. Rozmovits, P. Hewitson, P. Rose, J. Austoker, and E. Watson, "Bowel cancer screening in England: a qualitative study of GPs'attitudes and information needs," BMC Family Practice, vol. 7, article no. 53, 2006.

[20] K. Kamposioras, D. Mauri, P. Alevizaki et al., "Cancer screening in Greece. Guideline awareness and prescription behavior among Hellenic physicians," European Journal of Internal Medicine, vol. 19, no. 6, pp. 452-460, 2008.

[21] M. Sarfaty and R. Wender, "How to increase colorectal cancer screening rates in practice," CA Cancer Journal for Clinicians, vol. 57, no. 6, pp. 354-366, 2007.

[22] L. J. Finney Rutten, D. E. Nelson, and H. I. Meissner, "Examination of population-wide trends in barriers to cancer screening from a diffusion of innovation perspective (1987-2000)," Preventive Medicine, vol. 38, no. 3, pp. 258-268, 2004.

[23] A. Miles, J. Cockburn, R. A. Smith, and J. Wardle, "A perspective from countries using organized screening programs," Cancer, vol. 101, S5, pp. 1201-1213, 2004. 


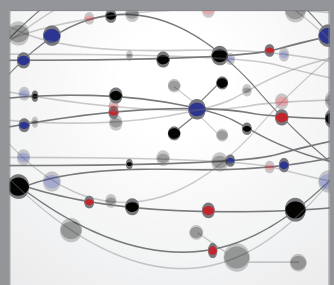

The Scientific World Journal
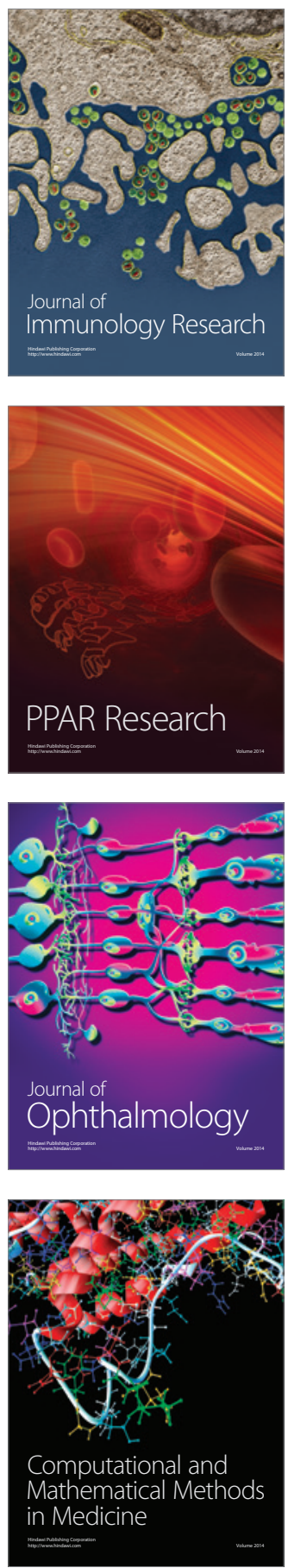

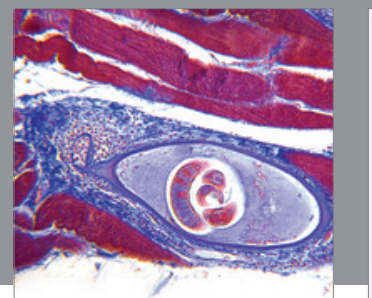

Gastroenterology

Research and Practice
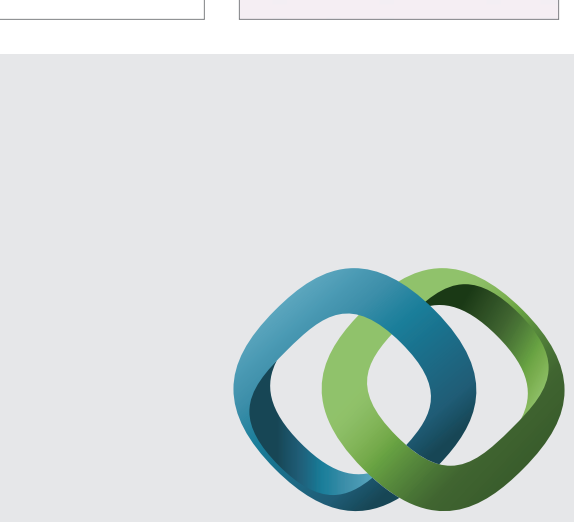

\section{Hindawi}

Submit your manuscripts at

http://www.hindawi.com
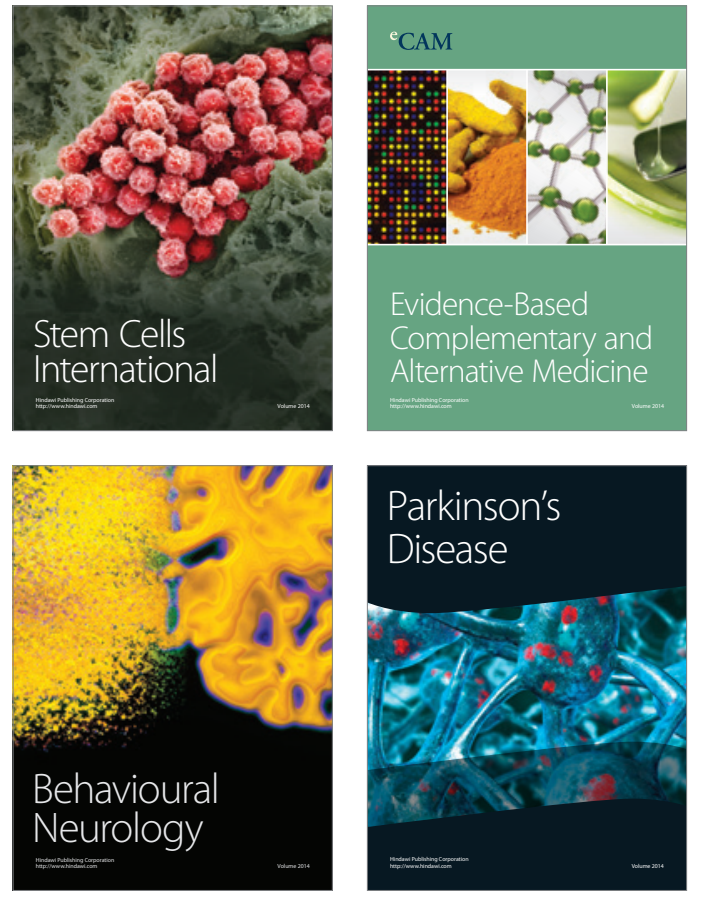
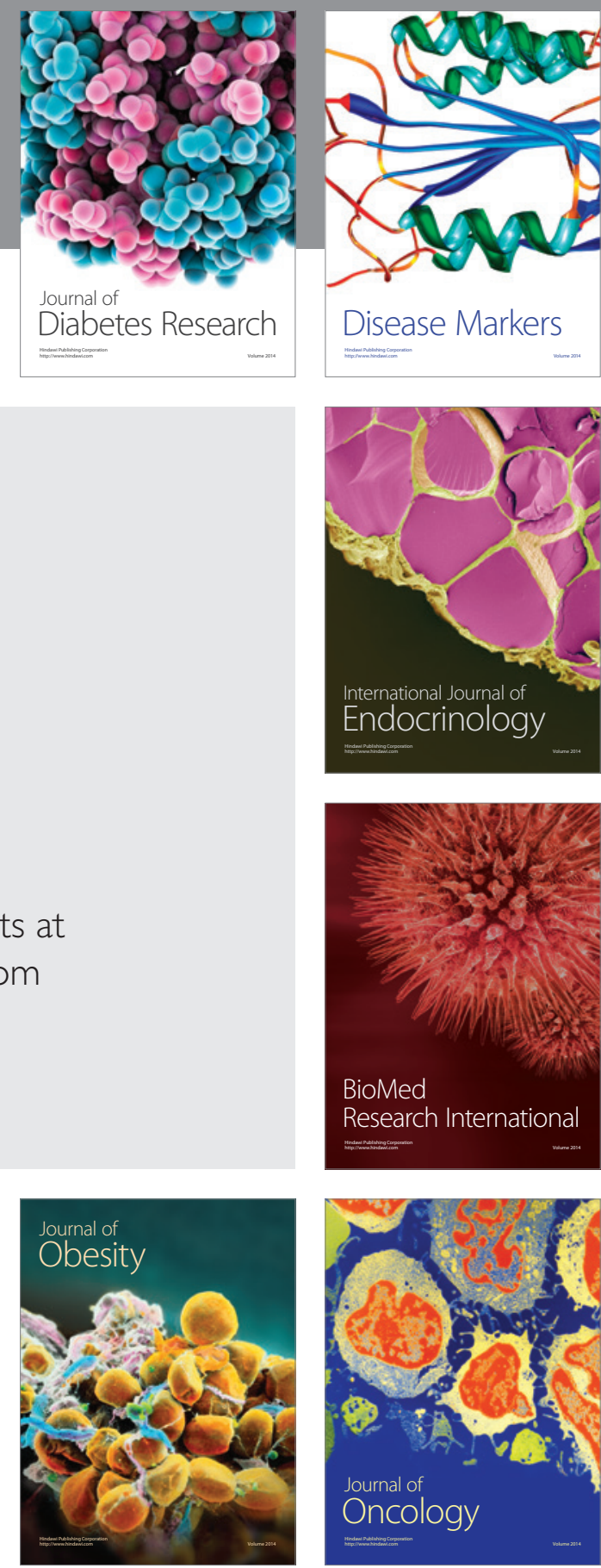

Disease Markers
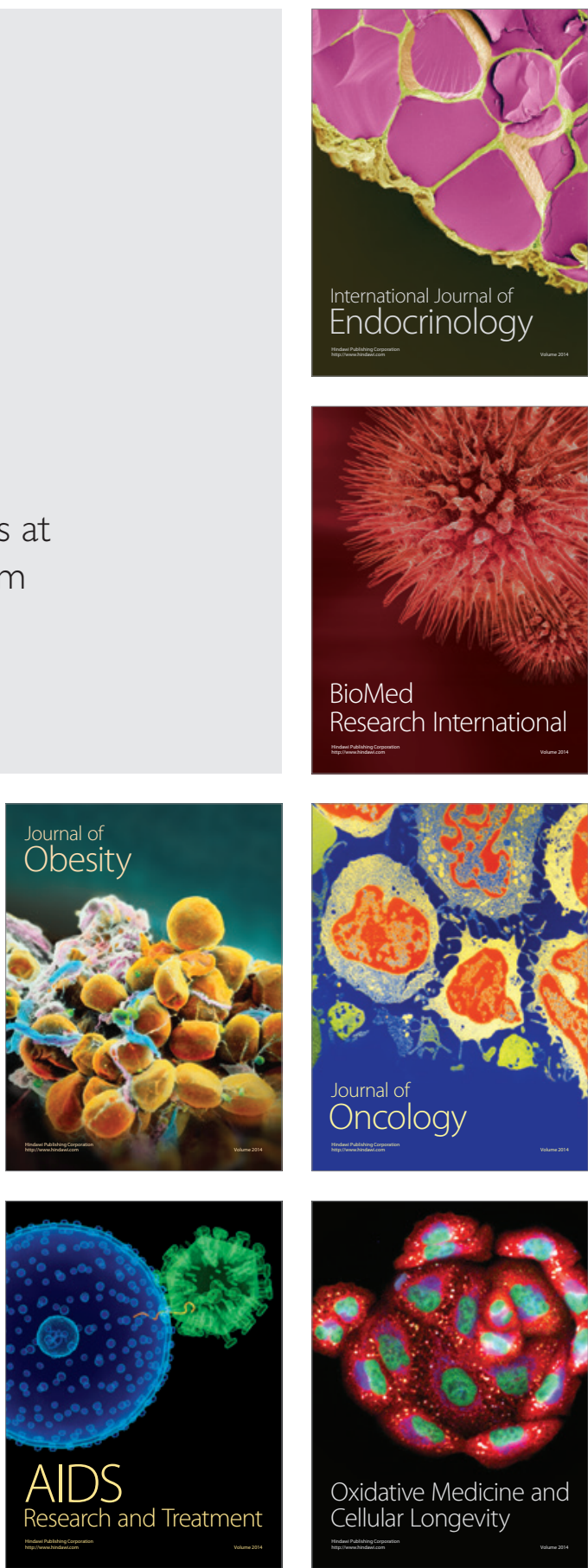